\title{
Spatial Dependence of the Site Index of Pinus taeda L. Production Forests, in the Southern Central Region of the State of Paraná, Brazil
}

\author{
Maite dos Santos Ribeiro ${ }^{1}$, Julio Eduardo Arce $^{2}$, Afonso Figueiredo Filho ${ }^{1} \&$ Marcos Felipe Nicoletti $^{3}$ \\ ${ }^{1}$ State University of Midwest Paraná, Irati, Brazil \\ ${ }^{2}$ Federal University of Parana, Curitiba, Paraná, Brazil \\ ${ }^{3}$ State University of Santa Catarina, Lages, Santa Catarina, Brazil \\ Correspondence: Maite dos Santos Ribeiro, Department of Forestry Engineering, State University of Midwest \\ Paraná (UNICENTRO), Irati, Brazil. E-mail: maiteribeiroeng@gmail.com
}

Received: May 18, 2019

doi:10.5539/jas.v11n13p319
Accepted: June 29, 2019 Online Published: August 15, 2019

URL: https://doi.org/10.5539/jas.v11n13p319

\begin{abstract}
A spatial analysis of the site index used for the classification of Pinus taeda production forests was performed using dominant height data from 402 continuous inventory plots. The data were examined with simple descriptive statistics and fit with four semivariogram models by the GS + program. The best model was then used to predict the site index in unsampled areas by ordinary kriging in ArcView. All models showed that site index values exhibited spatial dependence, with the degree of spatial dependence ranging from strong to moderate. The spherical model was used for kriging. In this model, the degree of spatial dependence was $29 \%$ and the range was $5,330 \mathrm{~m}$, with a residual sum of squares (RSS) of 3.00 and coefficient of determination $\left(\mathrm{r}^{2}\right)$ of 0.776. Measured and predicted values were compared by cross-validation, which produced a linear regression of observed versus predicted value with a slope coefficient of 1.068, slope standard error of 0.070 , and intercept coefficient of -1.45 . The site classification map generated by kriging divided the studied forests into five classes. Before kriging, all of the forest stands had one global average value for the site index, but after kriging this was changed to there being two or three values of the site index for many stands. Ordinary kriging proved to be an optimal method for interpolating the site index of unsampled areas to permit their classification, as is the case for young plantations for which inventory samples have not yet been taken.
\end{abstract}

Keywords: site classification, geostatistics, kriging

\section{Introduction}

The Brazilian production forests, forest-based industry is known worldwide for the high productivity of its planted areas, according to IBÁ (2017), have 7.84 million hectares of planted trees, is responsible for $91 \%$ of all wood produced for industrial purposes in the country and $6.2 \%$ of the Brazilian GDP; also it is one of the industries with the greatest potential to help build a green economy. Of the total planted trees, the Pinus plantations occupy 1.6 million hectares and concentrate mainly in the south of the country, being led by the state of Paraná with $42 \%$ of total.

Pinus production forests are usually managed for multiple uses and can achieve mean annual increment (MAI) higher than $40 \mathrm{~m}^{3} / \mathrm{ha} /$ year in 18 -year-old trees for Pinus taeda. These levels of productivity are among the largest in the world for the species.

Scolforo and Machado (1988) stated that the classification of forest lands based on their potential for productivity is important for both the manager and the administrator of a forestry company because the index that expresses this productivity is a variable required in predictive models of present and future forest growth and production. This important method of classification is usually based on the stratification of forest settlements for inventory and cutting exploration, and therefore it must be considered in local and regional short- and long-term planning.

In many cases, the mean values of the site indices obtained in forest sites with the same class of soil can be differentiated. When soil properties are spatially dependent, geostatistical methodologies allow a useful spatial description of site characteristics to be obtained to provide production information (Bognola et al., 2008), which can consequently lead to better predictions of the consequent productivities of different forest sites. 
According to Scolforo (1997), 'Multifactorial Site Classification' is the most efficient procedure for the classification of forest productivity because it makes it possible to interpret a set of several factors at the same time. For example, this approach can allow one to identify whether such factors as precipitation, relative humidity, temperature, soil depth, and/or supplies of macro- and micronutrients, among others, best explain the quality of the site alone or in combination.

However, obtaining information on all these variables becomes a costly process that is not realistically attainable for many companies in the forestry sector. There are other methods that allow the productive capacity of different sites to be assessed, and according to Scolforo and Machado (1988) the most widely used of these is the determination of site index values based on the average height of the dominant trees at a site. This is because this is a more practical and efficient methodology to estimate the productivity potential of each site that is not affected by silvicultural treatments, and which is also based on a measurement that is easily obtained by the traditional sampling methods used during forest inventory activities.

The current forestry situation has demanded that managers move away from traditional approaches to forest assessment, and instead adopt the techniques of precision forestry by integrating data within a geographic information system (GIS). In this context, a simple and easily accessible alternative approach would include the spatial analysis of the site indices obtained based on assessing the dominant heights of the trees in inventory plots by traditional sampling methods combined with new approaches using spatial information.

Thus, by performing the geostatistical analysis of site index values, managers could produce maps of the classification of different sites, and from them redefine their management units.

The traditional statistical methods used to take forest inventories use a central measure (mean) and a dispersion (variance) to describe the site index, without considering the possible correlations among neighboring observations. Therefore, they do not sufficiently exploit the spatial relationships that may exist among sampling units. Conversely, geostatistical methods can better evaluate the spatial dependence of the structure of the dendrometric characteristics of the species in a study area with physical environmental variables, which can allow results to be obtained that can adequately exploit the spatial relationships existing within the data; in other words, geostatistics is a statistical methodology that explores the existing relationships among sampling units.

The spatial modeling of site index would allow a quantitative description of the variability among sites to be obtained, in addition to making non-biased estimates of the minimum variance in site index values in unsampled locations possible. This means that, in addition to the identification of site classes by generating maps, we could also use this approach to subdivide plots that previously had a general average site index value applied to them, as well as determine the site index values of young plantations in which plots have not yet been sampled by traditional inventory approaches.

The use of the site index obtained based on dominant height in the forest environment is strengthened by the high representativeness of the site environment it provides and the ease of obtaining the data needed to calculate it. It remains unknown whether this variable has spatial dependence, and its spatial relations with the environment have also not yet been assessed.

Therefore, the objective of this study was to assess the variability in this site index through spatial analysis to classify the productivity of the production of Pinus taeda forest, in the southern central region of the state of Paraná, Brazil, while considering the existing spatial relationships among forest sites.

\section{Materials and Methods}

This study was carried out in production forests of Pinus taeda L. with a total area of 2,111 hectares, located in the municipalities of Bituruna and General Carneiro, in the southern central region of the state of Paraná, Brazil. These forests' central coordinates were located at a latitude of $26.1834^{\circ} \mathrm{S}$, a longitude of $51.3303^{\circ} \mathrm{W}$, and an average altitude of $985 \mathrm{~m}$ above sea level.

The dominant climate is subtropical humid mesothermic, or Cfb according to the Köppen classification system, and is characterized by cool summers and harsh winters with severe and frequent frosts concentrated in the months of March to September. It does not present a characteristic dry season and has average temperatures in the warmer months below $22{ }^{\circ} \mathrm{C}$ and in the colder months below $18{ }^{\circ} \mathrm{C}$. The rainfall regime is irregular, with a decrease in the winter period and higher rainfall intensity in the summer. The average annual rainfall is 1,600 to $1,770 \mathrm{~mm}$. Regarding relative humidity, mean indices between 80 and $85 \%$ predominate in this region.

The study area was located on the third highest plateau in Paraná, which is one of the most extensive relief units in the state, and contains representatives of the rock formations of the Paraná Basin. The predominant relief in this region is wavy, and the predominant soils there are cambissols and acrisols. 
The data from sample plots continuously used for forest inventory sampling for 5 to 10 years or from 13 to 15 years, depending to the quality of the site, were used. A total of 402 sample plots was used.

The variable used to characterize the quality of each site was the site index (SI). The determination of the dominant height (DOMH) of the trees in each site, which is related to each site's productive capacity, was obtained by the method of Assmann (1961, p. 435), which considers the dominant height as the average height of the one hundred trees with the largest diameter-at-breast-height (DBH) values in an area of one hectare.

As the ages of the measured trees varied among stands, all of the dominant heights measured were projected to those of trees 15 years of age.

Initially, the data were used to calculate simple descriptive statistics, including indices of central tendency (mean and median), dispersion (variance, standard deviation, maximum, and minimum values) and form (kurtosis, symmetry coefficients, and graphs of normality). These were calculated in the statistical program GS +10.0 and subjected to several tests of normality, at the significance level of $5 \%$.

To describe and model the spatial patterns in the variable of interest (Pinus taeda site index), geostatistics were used to produce and adjust semivariograms in the GS +10.0 program. Four semivariogram models were tested (Table 1). The best model among these semivariograms was chosen as the one with the smallest residual sum of squares (RSS), highest coefficient of determination $\left(\mathrm{r}^{2}\right)$, and with a greater relative simplicity compared to those of the other models.

Table 1. Semivariogram models fit to Pinus taeda site index values

\begin{tabular}{ll}
\hline Model & Equation \\
\hline Spherical & $\gamma(\mathrm{h})=\mathrm{C}_{0}+\mathrm{C}\left[\left(\frac{3}{2}\right)\left(\frac{\mathrm{h}}{\mathrm{A}}\right)-\left(\frac{1}{2}\right)\left(\frac{\mathrm{h}}{\mathrm{A}}\right)^{3}\right]$ \\
Exponential & $\gamma(\mathrm{h})=\mathrm{C}_{0}+\mathrm{C}\left(1-\mathrm{e}^{-\mathrm{h} / \mathrm{A}}\right)$ \\
Gaussian & $\gamma(\mathrm{h})=\mathrm{C}_{0}+\mathrm{C}\left(1-\mathrm{e}^{-\mathrm{h}^{2} / \mathrm{A}^{2}}\right)$ \\
Linear & $\gamma(\mathrm{h})=\mathrm{C}_{0}+\mathrm{p}(\mathrm{h})^{\mathrm{A}}$ \\
\hline
\end{tabular}

Note. $\gamma(\mathrm{h})=$ semivariogram; $\mathrm{C}_{0}=$ nugget and $\mathrm{C}=$ sill.

The anisotropy of each of the semivariograms was verified and corrected in directions of $0,45,90$, and 135 degrees to obtain isotropic semivariograms.

After the adjustment of each of the models, the degree of the spatial dependence (SDD\%) in the model was obtained, which represented the percentage of the sill $\left(\mathrm{C}^{\prime}=\mathrm{C}+\mathrm{C}_{0}\right)$ occupied by the nugget effect $\left(\mathrm{C}_{0}\right)$. According to Cambardella et al. (1994), the closer this value is to one, the weaker the spatial dependence of the dependent variable in the model is, and thus models could be classified as follows:

a) Strong spatial dependence: the nugget effect is less than or equal to $25 \%$ of the sill;

b) Moderate spatial dependence: the nugget effect is between 25 and $75 \%$ of the sill;

c) Weak spatial dependence: the nugget effect is between 75 and $100 \%$ of the sill;

d) Spatially independent variable: the nugget effect is equal to $100 \%$ of the sill, in which case the semivariogram has a purely nugget effect.

The best semivariogram model was then used to predict the site index values of unsampled locations by performing interpolation by ordinary kriging with the GIS software ArcView 9.1, with the Geostatistical and Spatial Analyst extensions.

The estimated site index values calculated by kriging were evaluated by determining the errors committed in the process of estimation by cross-validation. A site classification map was then constructed from the kriging results by assigning each plot a site index value.

\section{Results and Discussion}

When we calculated descriptive statistics for our data, we obtained a mean site index value of 21.26, median of 21.34 , standard deviation of 1.62 , kurtosis of 2.23 , asymmetry of -0.36 , and coefficient of variation of $7.6 \%$. The normality tests verified that the site index data had a normal distribution. 
Further evidence of the symmetry of the distribution of these data was also provided by the similarity of the mean and median values obtained. According to Cressie (1993), all methods of linear geostatistical inference that have been developed based on stochastic modeling depend on the assumption that the data have a normal distribution. However, according to Mello et al. (2005), the data do not need to be normally distributed for geostatistics to be applied to them. Normality only improves some of the statistical properties within geostatistical analyses, such as maximum likelihood, and guarantees spatial continuity, which is strongly affected by the absence of normality (Cressie, 1993).

Data analysis by histogram generation is important for the observation of outliers. These values may cause the conclusion of false spatial correlation because they can distort the variance in the nugget effect. No candidate outlier values representing such potential causes of discrepancies were observed herein.

The semivariogram analysis showed that the site index variable presented spatial dependence, and could thus be adjusted by geostatistical modeling. Table 2 shows the adjustment of the semivariograms obtained.

Table 2. Parameters and statistics for the semivariograms fit to data for Pinus taeda site index values

\begin{tabular}{lllllll}
\hline Model & $\mathbf{C}_{\mathbf{0}}$ & $\mathbf{C}_{\mathbf{0}}+\mathbf{C}$ & $\mathbf{R}(\mathbf{m})$ & $\mathbf{S D D} \%$ & $\mathbf{r}^{\mathbf{2}}$ & $\mathbf{R S S}$ \\
\hline Linear & 1.4616 & 4.1381 & 5,791 & $35 \%$ & 0.7030 & 3.98 \\
Spherical & 1.0680 & 3.7360 & 5,330 & $29 \%$ & 0.7760 & 3.00 \\
Exponential & 1.1000 & 4.8530 & 12,690 & $23 \%$ & 0.7330 & 3.57 \\
Gaussian & 1.4630 & 3.8950 & 5,075 & $38 \%$ & 0.7950 & 2.74
\end{tabular}

Note. $\mathrm{C}_{0}=$ nugget effect; $\mathrm{C}_{0}+\mathrm{C}=$ sill; $\mathrm{R}=$ range; $\mathrm{SDD} \%=$ degree of spatial dependence $(\%) ; \mathrm{r}^{2}=$ coefficient of determination; RSS $=$ residual sum of squares.

The site index variable presented spatial dependence in all of the tested models, with the degree there of varying from strong to moderate. This demonstrates that kriging can be used in the classification of forest sites, agreeing with the results found by Hock et al. (1993), Gunarsson et al. (1998), Ortiz et al. (2006), Mello et al. (2005), Montes et al. (2006), Bognola et al. (2008), and Palmer et al. (2010).

Focusing on the spherical model, which was concluded to be the best model herein (see below, and Table 2), the nugget effect on the site index corresponded to $29 \%$ of the sill, meaning that $71 \%$ of the variability in the site index was explained by the spatial correlation of this variable. According to Vieira (1998) and Isaaks and Srivastava (1989), the lower the percentage of the sill that is due to the nugget effect (SDD\%) is, the greater the similarity will be between neighboring values and the spatial continuity of the phenomenon under investigation, and the lower the variance in the estimates will be; therefore, this means that there can be greater confidence in the estimates made using the model.

The nugget effect $\left(\mathrm{C}_{0}\right)$, also called random variance, reflects the uncertainty in the variance in the dependent variable over small distances, which is mainly due to the lack of knowledge of the spatial distribution of the variable under study (Yamamoto \& Landim, 2013). Hock et al. (1993), using geostatistics to estimate site index values in Pinus radiata, and Montes et al. (2006), studying the use of kriging to predict the site indices and ages of Pinus pinea forests, both found higher nugget effect values than that observed in this study. However, Mello (2004), when studying the spatial dependence of the dendrometric characteristics of Eucalyptus grandis, found lower nugget effect values than ours, but considered these to be high values due to them corresponding to what Aubry and Debouzie (2001) had concluded nugget effect values are higher in studies involving ecological variables.

The average spatial range in the adjusted models with a high degree of spatial dependence for the definition of site index classes was $5,399 \mathrm{~m}$. This reveals that for distances exceeding this range value, the data should be treated as spatially independent, suggesting that the site index plots used in forest inventory efforts can be separated from each other at this distance. According to Landim (2006), a large range value allows for the use of a more widely spaced sampling program, and offers higher-quality interpolated data estimates for map production. Bognola et al. (2008), studying the variability in Pinus taeda productivity as a function of soil clay content, found spatial dependence in their data up to a range of $6,021 \mathrm{~m}$.

According to Yamamoto and Landim (2013), the spherical, exponential, and Gaussian models explain most spatial phenomena, and the optimal modeling of a semivariogram is a process that involves several attempts, in which experience weighs heavily in selecting the best modeling approach. Landim (2006) also noted that the 
spherical model is equivalent to the normal distribution of classical statistics. Several studies have found that the best adjustments for their semivariograms were obtained using the Gaussian and spherical models; for example, this was the case for Ortiz et al. (2006), Biondi et al. (1994) and Gunnarsson et al. (1998) when studying several variables for the genus Pinus, and for Pelissari et al. (2014) and Mello et al. (2005) when studying production forests of other species.

The Gaussian and spherical models achieved the best fit in this study in terms of their $r^{2}$ and RSS values. Yamamoto and Landim (2013) noted that in many cases the sensitivity of a particular data set and the knowledge of those working with it about the variable in question is a fundamental importance in the selection of the best semivariogram model. Sometimes, it is preferable to select a model with a slightly smaller $\mathrm{r}^{2}$ or higher RSS than the one suggested by the statistical program as the best, but which better represents the data. In general, the simpler the adjusted model is, the better, and no excessive importance should be given to a model that fits small fluctuations possibly representing noise in the data.

The Gaussian model is a transitive model, which is often used to model extremely continuous phenomena (Isaaks \& Srivastava, 1989). The theoretical Gaussian model does not reach $100 \%$ of the sill, but rather reaches the same percentage thereof as the exponential model, which is approximately $95 \%$. This model is characterized by presenting parabolic behavior near the origin (Andriotti, 2003, p. 165). The spherical model is the only one of the models tested herein that truly reaches the sill, and which also has a small nugget effect compared to the value of the sill (Andriotti, 2003, p. 165). Therefore, some authors, such as Trangmar et al. (1987), have argued that the spherical model is the most appropriate to use to describe the behaviors of plant and soil attributes.

Because the spherical model is a simpler model that truly reaches the level of the sill, and also because the $\mathrm{r}^{2}$ and RSS values were very close between the Gaussian and spherical models herein, the spherical model (Figure 1) was chosen for use in kriging in the present study. Moreover, it is known that the site index variable does not have parabolic behavior near the origin, and thus is not well represented by the Gaussian model.

Isotropic Variogram

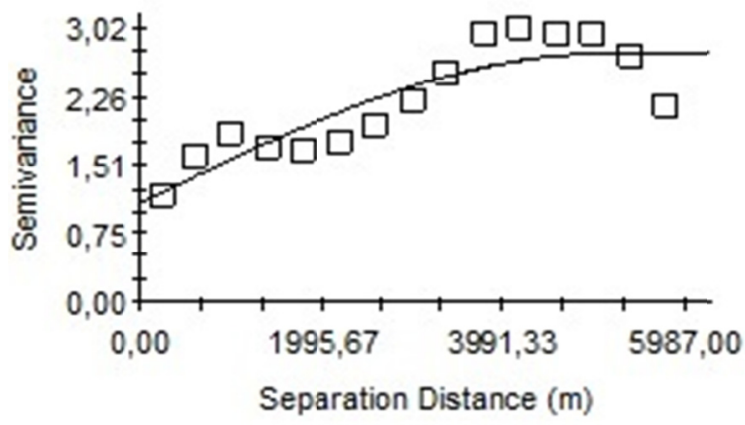

Figure 1. Spherical semivariogram model fit to Pinus taeda site index data

Anisotropy in the semivariogram was similar in all directions, and therefore was not corrected, so interpolation was performed using the isotropic semivariogram.

The comparison between the real and estimated values in the cross-validation of site index values (Figure 2) produced a regression with a slope coefficient of 1.068 with a standard error of 0.070 , indicating that this slope was statistically indistinguishable from 1 . The intercept coefficient of this regression was -1.45 , which can be considered to be statistically close to zero. These were optimal conditions for these estimates, indicating good agreement between observed and predicted values. However, the coefficient of determination $\left(\mathrm{r}^{2}\right)$ was equal to 0.373, which is considerably low, but due to the large number of observations and knowing that this coefficient is strongly influenced by the number of pairs, we can consider it as satisfactory, and still conclude good agreement. 


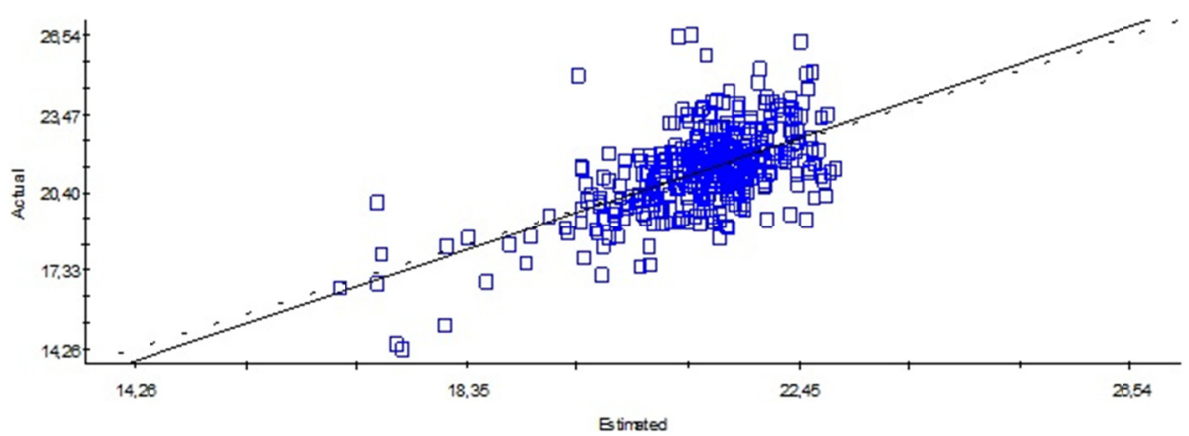

Figure 2. Graphical representation of the cross-validation of measured (actual) and predicted (estimated) Pinus taeda site index values produced by kriging

According to Hock et al. (1993), due to the smoothing technique applied to kriging surfaces, it is expected that lower site index values will be overestimated, and higher site index values will be underestimated. However, since the estimation procedure is global, the expected mean difference should be very close to zero (Table 3). According to Andriotti (2003, p. 165), the closer the mean value of the differences obtained by cross-validation is to zero, the better the estimates made by kriging are.

Table 3. Cross-validation of measured (actual) and predicted (estimated) of Pinus taeda site index values produced by kriging

\begin{tabular}{llll}
\hline & Actual SI (m) & Estimated SI (m) & Difference $|\mathbf{m}|$ \\
\hline Average & 21.254 & 21.244 & 0.01 \\
Standard deviation & 1.61 & 0.88 & 0.72 \\
Minimum & 14.26 & 17.14 & 2.88 \\
Maximum & 26.49 & 23.11 & 3.38 \\
\hline
\end{tabular}

When analyzing the frequency distributions of the real and estimated SI values on the same scale (Figure 3), it was observed that after kriging the values were concentrated close to the average, overestimating the SI of low-SI sites and underestimating that of high-SI sites. It was noteworthy that the amplitude of the distribution was also reduced because the Kriging method softens the overall distribution.
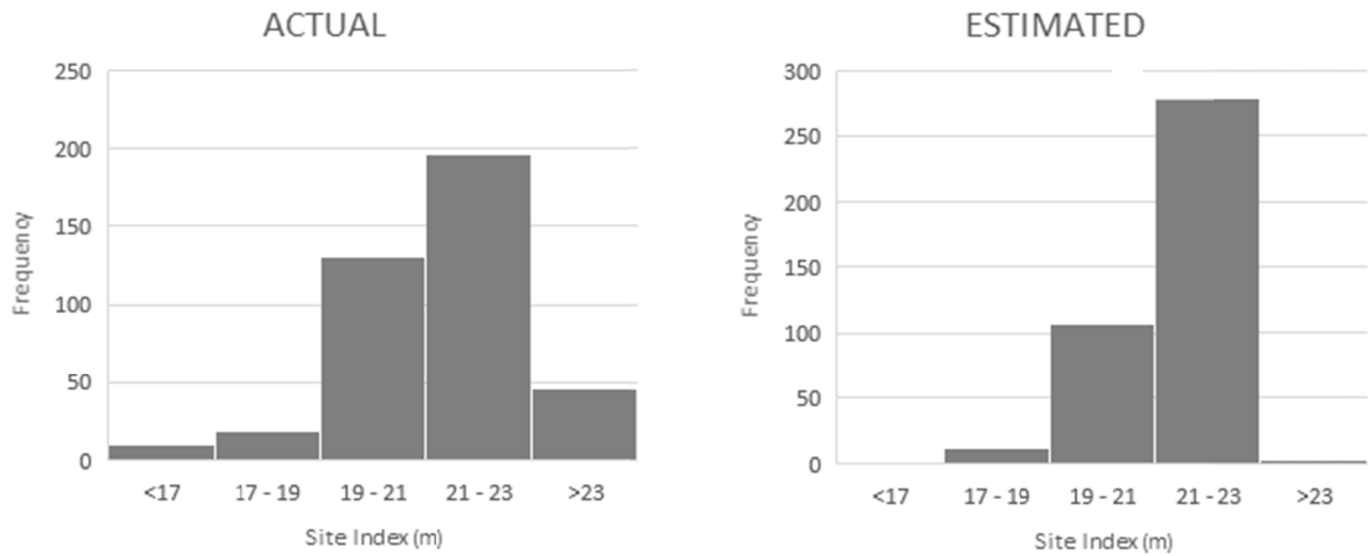

Figure 3. Frequency distributions of measured (actual) and predicted (estimated) Pinus taeda site index values produced by kriging

From the semivariogram, the degree of spatial dependence among site index values could be obtained, which is essentially a measure of the variability in site indices that occurs due to the distances among sites. The kriging procedure uses this information to find the optimum weights to associate with the samples to estimate the value 
of the dependent variable at a particular point in space, and the variance of the kriging estimates is independent of the values of the points used to obtain the estimators and measures only the spatial configuration of the data. In other words, kriging does not guarantee that the map obtained has the same distribution (histogram), the same variance, or the same semivariogram as the original data because, by the very nature of this method, it merely produces a map with smoothed values that must be inversely proportional to the density of the sampled points.

With the smoothed map generated by the kriging can use the classification of sites to express the stands productivity, including the unsampled plots and reclassify or divide large stands that previously had a general average. Usually, all future forest production used in strategic planning are obtained from the sites that were sampled. Sites without an inventory sample plots receive an average of the previous rotations or an average based on the empirical knowledge of the area. As the adjusted variable had spatial dependence on the spherical model, kriging can be used as a way of classifying places in locations without an inventory sample, until the distance known as "range".

Using the adjusted spherical semivariogram, it was possible to obtain a mesh of interpolated values to visualize the behavior of the site index in the classification map of Pinus taeda sites, which were then divided into five classes based on the values obtained (Figure 4).

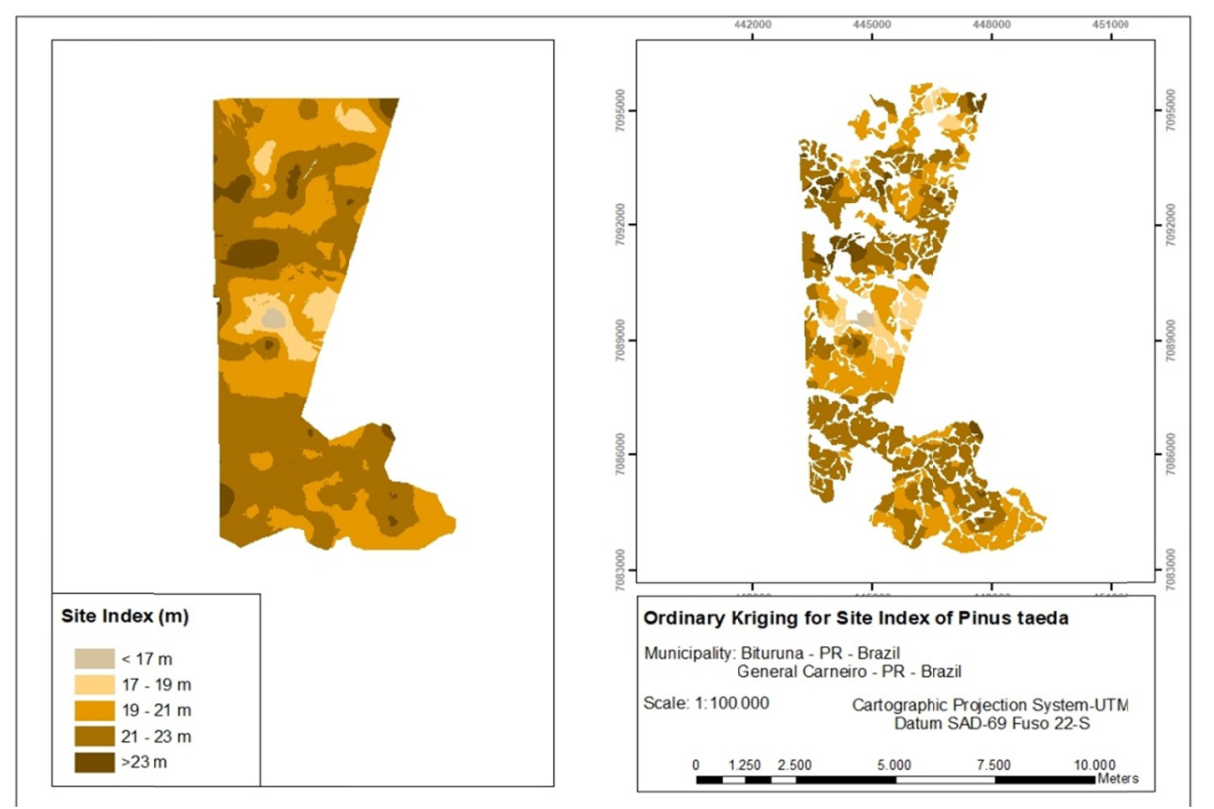

Figure 4. Spatial distribution map of Pinus taeda site index values generated by kriging

The site classification map generated by kriging (Figure 4) provided a new format by which the division of sites could be done, in which the stands that had one global average value for their site index were divided into those with two or three site index values after kriging. Ordinary kriging thus proved to be an optimal method of interpolating the site index values of unsampled areas based on which they could then be classified, as is often the case for young plantations in which inventory sampling has not yet been performed.

\section{Conclusion}

For the studied area, it was concluded that:

$>\quad$ The site index variable has spatial dependence and can use be used with kriging as a tool for classifying sites.

$>\quad$ The spatial dependence structure is similar in all directions, therefore presupposing the spatial continuity of this phenomenon.

The range found was $5,330 \mathrm{~m}$, showing that inventory plots separated by distances lower than this should not be treated as independent in the determination of the site index variable. 
> Kriging was shown to be an optimal method for the proper classification of sites in unsampled locations by interpolating their site index values, as is the case for young plantations for which there are not yet inventory samples.

$>\quad$ The mapping of site classes by ordinary kriging proved to be a simple, practical, and low-cost technique.

\section{References}

Andriotti, J. L. S. (2003). Fundamentos de estatística e geoestatística. São Leopoldo, UNISINOS.

Assmann, E. (1961). Waldertragskunde. Muenchen: BLV Verlagsgessellschaft.

Aubry, P., \& Debouzie, D. (2001). Estimation of the mean from a two-dimensional sample: The geostatistical model-based approach. Ecology, 82(5). https://doi.org/10.2307/2680004

Biondi, F., Myers, D. E., \& Avery, C. C. (1994). Geostatistically modeling stem size and increment in an oldgrowth forest. Canadian Journal of Forest Research, 24(7), 1354-1368. https://doi.org/10.1139/x94-176

Bognola, I. A., Junior Ribeiro, P. J., Silva, E. A. A. da, Lingnau, C., \& Higa, A. R. (2008). Modelagem uni e bivariada da variabilidade espacial de rendimento de Pinus taeda L. Floresta, 38(2), 373-385. https://doi.org/ 10.5380/rf.v38i2.11632

Cambardella, C. A., Moorman, T. B., Novak, J. M., Parkin, T. B., Karlen, D. L., Turco, R. F., \& Konopka, A. E. (1994). Field scale variability of soil properties incentral Iowa soils. Soil Science Society of America Journal, 58(5), 1501-1511. https://doi.org/10.2136/sssaj1994.03615995005800050033x

Cressie, N. (1993). Statistics for spatial data (p. 900). New York: Wiley. https://doi.org/10.1002/9781119 115151

Gunnarson, F. (1998). On the potential of krigagem for forest management planning. Scandinavian Journal of Forest Research, 13(2), 237-245.

Höck, B. K., Payn, T. W., \& Shirley, J. (1993). Using a geographic information system and geostatistics to estimate site index of Pinus radiata for Kaingaroa forest. New Zealand Journal of Forestry Science, 23, 264-277.

IBÁ. (2017). Indústria brasileira de árvores 2017. Brasília, Brazil.

Isaaks, E. H., \& Srivastava, R. M. (1989). An introduction to applied geostatistics. New York: Oxford University Press.

Landim, P. M. B. (2006). Sobre Geoestatística e mapas. Terrae Didatica, 2(1), 19-33. https://doi.org/10.20396/ td.v2i1.8637463

Mello, J. M. de. (2004). Geoestatística Aplicada ao Inventário Florestal (Doctoral thesis. School of Agriculture Luiz de Queiróz, University of São Paulo Piracicaba).

Mello, J. M. de, Batista, J. L. F., Oliveira, M. S. de, \& Ribeiro Junior, P. J. (2005). Estudo da dependência espacial de características dendrométricas para Eucalyptus grandis. Cerne, 11(2), 113-126.

Montes, F., Hernandez, M., Calama, R., \& Canellas, I. (2006). Extended length rotation to integrate timber and pine nut production with the conservation of structural diversity in a Pinus pinea (L.) forest. EDP Sciences, 773-781. https://doi.org/10.1051/forest:2006059

Ortiz, J. L., Vettorazzi, C. A., Couto, H. T. Z. do, \& Gonçalves, J. L. de M. (2006). Relações espaciais entre o potencial produtivo de um povoamento de eucalipto e atributos do solo e do relevo. Scientia Forestalis, 72 , 67-79.

Palmer, D. J., Watt, M. S., Kimberley, M. O., Höck, B. K., Payn, T. W., \& Lowe, D. J. (2010). Mapping and explaining the productivity of Pinus radiata in New Zealand. NZ Journal of Forestry, 55(1), 15-21.

Pelissari, A. L., caldeira, S. F., \& Santos, V. S. dos. (2014). Variabilidade espacial dos atributos químicos do solo em povoamentos de Tectona grandis. Cerne, 20(3), 377-384. https://doi.org/10.1590/0104776020142 0031437

Scolforo, J. R. S. (1997). Biometria Florestal-Módulo: Métodos para classificação de sítios florestais. UFLA/FAEPE/DCF, Lavras.

Scolforo, J. R. S., \& Machado, S. A. (1988). Curvas de índice de sitio para plantações de Pinus elliottii no estado do Paraná e Santa Catarina. Floresta, 23(1-2), 140-158. 
Trangmar, B. B., Yost, R. S., Wade, M. K., Uehara, G., \& Sudjadi, M. (1987). Spatial variation of soil properties and rice yield on recently cleared land. Soil Science Society of America Journal, 51, 668-674. https://doi.org/10.2136/sssaj1987.03615995005100030021x

Vieira, S. R. (1998). Geoestatística em estudos de variabilidade espacial. Campinas: IAC.

Yamamoto, J. K., \& Landim, P. M. B. (2013). Geoestatística: conceitos e aplicações. São Paulo, Oficina de Textos.

\section{Copyrights}

Copyright for this article is retained by the author(s), with first publication rights granted to the journal.

This is an open-access article distributed under the terms and conditions of the Creative Commons Attribution license (http://creativecommons.org/licenses/by/4.0/). 